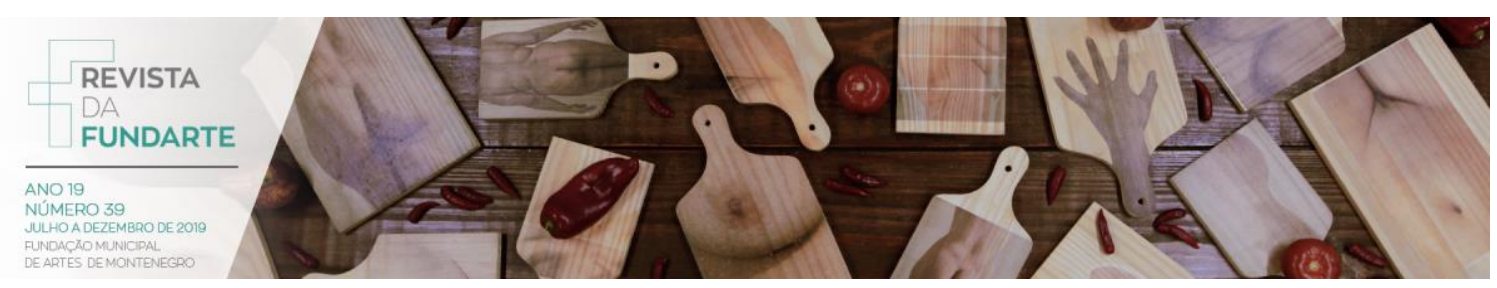

\title{
ENCONTROS COM A ARTE EM AUTOBIOGRAFIAS DE LICENCIANDAS EM PEDAGOGIA
}

Maria Emilia Sardelich

SARDELICH, Maria Emilia. Encontros com a arte em autobiografias de licenciandas em pedagogia. .Revista da FUNDARTE, Montenegro, p.69-88, ano 19, no 39, julho/dezembro de 2019.

Disponível em: http://.seer.fundarte.rs.gov.br/index.php/RevistadaFundarte/index $>20$ de dezembro de 2019. 


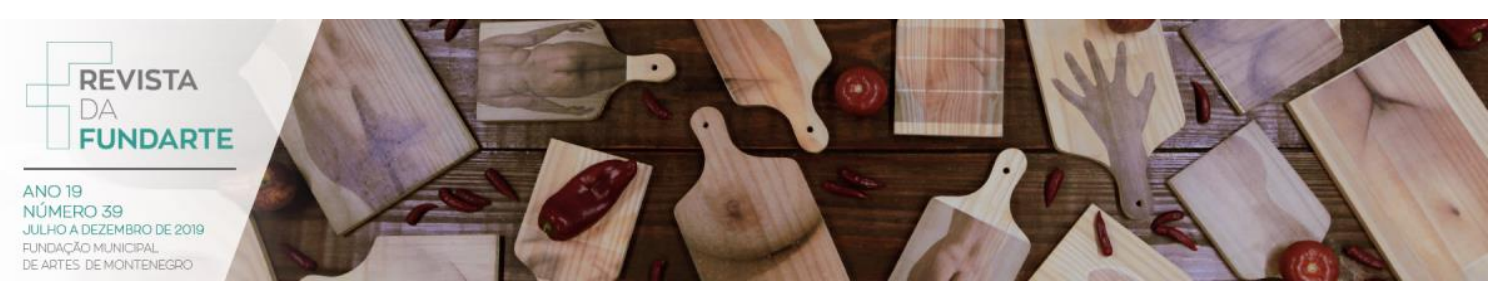

\title{
ENCONTROS COM A ARTE EM AUTOBIOGRAFIAS DE LICENCIANDAS EM PEDAGOGIA
}

Maria Emilia Sardelich ${ }^{1}$

\begin{abstract}
Resumo: Este artigo apresenta relatos de licenciandas em Pedagogia, sobre seus encontros com a arte. A metodologia da pesquisa narrativa trata as autobiografias como fonte de investigação para indagar sobre a formação em arte, produzir conhecimento sobre essa formação como também perceber o seu sentido para as licenciandas. Ao se referirem às práticas artísticas do contexto familiar, as narrativas são poéticas, emotivas, contrastando com uma árida exposição referente ao tempo escolar. A prática artística na escola ganhou pouco sentido, o que requer uma desaprendizagem da experiência escolar e da narrativa da arte como autoexpressão individual para a da arte relacional, que decolonize os conceitos de arte e estética e desobrigue a subjetividade.

Palavras-chave: Ensino de Arte; Prática Docente; Autobiografia.
\end{abstract}

\section{ENCOUNTERS WITH ART IN AUTOBIOGRAPHIES OF UNDERGRADUATES IN PEDAGOGY}

\begin{abstract}
This article presents narratives of undergraduates in Pedagogy about their encounters with art. From the methodological framework of narrative research, the autobiographies were thought as a source and research line, either to inquire about the formation in art and to produce knowledge about this qualification, as well as to perceive its meaning for the undergraduates. Artistic practices of the school context have made little sense, since the undergraduates do not feel able to work with them, requiring then an unlearning process, a way to discount the narrative of the individual self-expression for a relational art, to decolonize the concepts of art and aesthetics to release subjectivity.

Keywords: Teaching of Art; Teaching Practice; Autobiography.
\end{abstract}

\section{INTRODUÇÃO}

Há algum tempo dedico-me a investigar a formação em arte que ocorre em espaços formais e não formais de aprendizagem, esses territórios e redes biotecnológicas que acompanham as trajetórias de vida de indivíduos e grupos, nos quais também acontecem processos interativos de aprendizagem. Neste artigo apresento parte do processo de mediação que realizo em um espaço formal do ensino superior, com licenciandas em Pedagogia, no componente curricular Ensino de Arte, ofertado no quinto semestre do turno diurno e sexto semestre no noturno, da Universidade Federal da Paraíba (UFPB).

\footnotetext{
${ }^{1}$ Professora da Universidade Federal da Paraíba (UFPB), Centro de Educação (CE), Departamento Metodologia da Educação (DME) e Programa Associado de Pós-Graduação em Artes Visuais (PPGAV UFPB/UFPE). Líder do Grupo de Pesquisa em Ensino de Artes Visuais (GPEAV), vinculado ao PPGAV UFPB/UFPE. Doutora em Educação pela Universidade Federal da Bahia (UFBA, 2001).
}

SARDELICH, Maria Emilia. Encontros com a arte em autobiografias de licenciandas em pedagogia. .Revista da FUNDARTE, Montenegro, p.69-88, ano 19, oㅜ 39, julho/dezembro de 2019.

Disponível em: http://.seer.fundarte.rs.gov.br/index.php/RevistadaFundarte/index $>20$ de dezembro de 2019. 


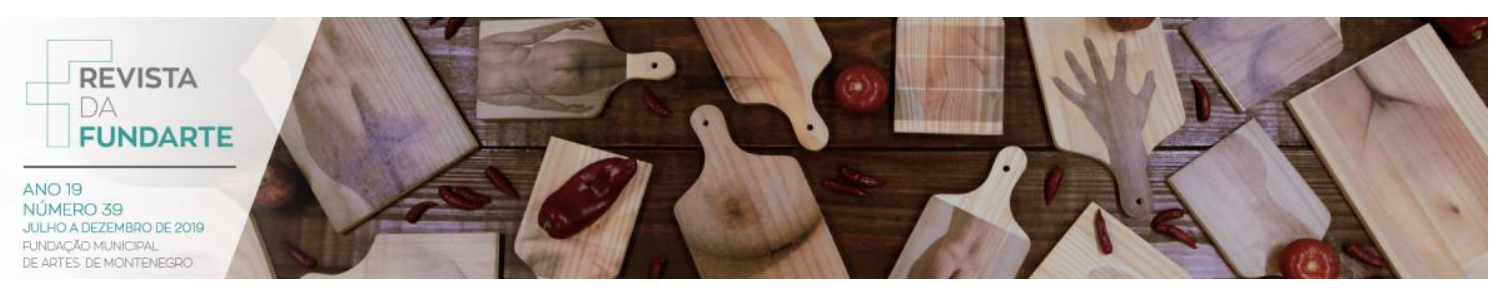

A Resolução CNE/CEB n.7/2010, que fixa as Diretrizes Curriculares Nacionais para o Ensino Fundamental, expõe a responsabilidade das pedagogas com as manifestações artísticas no espaço escolar. Por essa razão, a Resolução CNE/CP n.1/2006, que institui as Diretrizes Curriculares Nacionais para o Curso de Graduação em Pedagogia prevê que egressos dessa Licenciatura deverão estar aptos a ensinar arte, de forma interdisciplinar e adequada às diferentes fases do desenvolvimento humano. Considero que a capacidade para ensinar arte, de forma interdisciplinar e adequada às diferentes fases do desenvolvimento humano, prevista pela Resolução CNE/CP n.1/2006, requer o cuidado das licenciadas em Pedagogia com a própria formação, a percepção de como aconteceu, e continua acontecendo, essa formação ao longo de suas trajetórias de vida e, especialmente, na Educação Básica. Parto do entendimento de que a formação docente é um continuum, que se inicia muito antes da participação em um curso formal do ensino superior (MIZUKAMI, 2002) e se estende ao longo de todo o desenvolvimento profissional (MARCELO, 2009).

Assim como as crianças chegam à escola e trazem experiências que afetam suas construções cognitivas que se referem aos conteúdos estudados na escola, as licenciandas chegam aos cursos de Licenciatura com uma biografia em construção. Desse modo, as concepções sobre arte e seu ensino, que ocupam as bagagens das licenciandas também produzem seus modos de "planejar e desenvolver propostas nos contextos educacionais" (CUNHA, 2017, p.9).

A partir dessas referências, busquei compreender como vem acontecendo a formação em arte das licenciandas em Pedagogia e suas concepções prévias a partir de uma abordagem autobiográfica. Na contação da história de vida é a própria narradora, autora e protagonista, quem decide o que contar e calar, falar sobre seus percursos de vida, sua subjetividade. Utilizo o conceito de subjetividade referindo-me aos pensamentos e emoções conscientes e inconscientes do sujeito, o sentido de si e suas formas de entender sua relação com o mundo (GUATTARI, 1990).

Josso (2004) observa que o exercício autobiográfico possibilita transformar a vida, socioculturalmente, programada em uma obra inédita a construir, guiada por um aumento de lucidez decorrente do processo autorreflexivo. Também assinala 


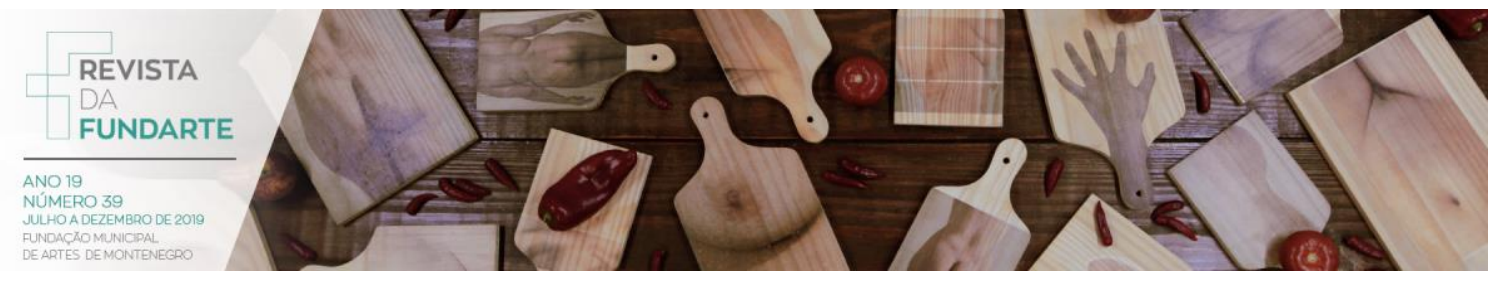

que essas possíveis transformações nos itinerários de vida exigem desaprendizagens (JOSSO, 2012), ou seja, o desembaraçar-se de hábitos mais ou menos antigos sobre os quais será necessário tomar consciência de que freiam a criação de um outro caminho ou uma vida criativa.

Metodologicamente, o estudo realizado com as licenciandas em Pedagogia na escrita autobiográfica de seus encontros com a arte, insere-se em uma abordagem narrativa (CLANDININ; CONNELY, 2015), pelo fato desta abordagem possibilitar uma compreensão do significado da experiência, sem perder de vista que a narrativa da pesquisadora é sempre dual, pois está imersa na experiência que deseja investigar. Passeggi e Souza (2017) afirmam que a pesquisa autobiográfica parte do pressuposto que a apropriação de instrumentos semióticos -as linguagens verbais e visuais- pelo sujeito para contar suas experiências podem ser reinterpretadas compondo um novo enredo de vida, uma reinvenção do sujeito "tornar-se um outro para construir-se como um si mesmo" (PASSEGGI; SOUZA, 2017 , p. 10). Portanto, este estudo utilizou as narrativas como fonte e método de investigação, para indagar sobre a formação em arte, produzir conhecimento sobre essa formação, como também para perceber o sentido que as licenciandas dão a essa formação.

Organizei a narrativa desta investigação do seguinte modo: inicialmente uma caracterização das estudantes de Pedagogia a partir de alguns dados quantitativos e qualitativos, obtidos no questionário da avaliação diagnóstica inicial. A seguir, analiso suas narrativas de formação em arte. Posteriormente, exponho a reflexão que este percurso de formação inspirou. Por fim, as considerações alcançadas até o momento.

\section{AS LICENCIANDAS EM PEDAGOGIA}

Participaram desta experiência 61 licenciandas, regularmente matriculadas que frequentaram assiduamente as aulas entre os meses de fevereiro e junho de 2018. Dentre as 61 matriculadas, 55 se identificaram como pertencentes ao sexo feminino e seis ao sexo masculino. A diagnose inicial se realizou por meio de um questionário individual. Os relatos autobiográficos sobre a formação em arte foram 


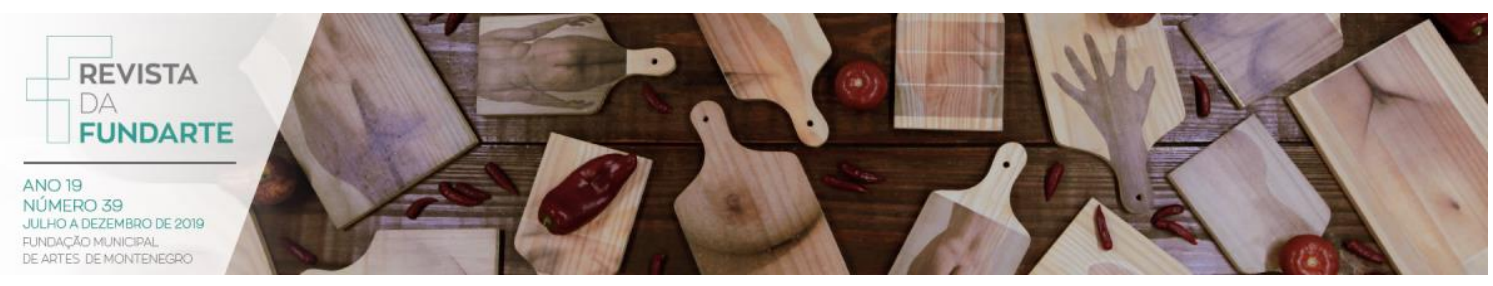

produzidos ao longo do semestre. Os trechos destacados em itálico e entre aspas, que apresento a partir deste ponto, foram extraídos das respostas aos questionários ou do relato individual das estudantes ao longo do componente curricular. Mantive a escrita das licenciandas, mesmo as heterodoxas concordâncias, respeitando seus linguajares e, somente em alguns casos, esclareço alguma palavra entre colchetes.

Sobre a formação em arte, ao longo da Educação Básica, 79\% das licenciandas reconheceram a formação em arte na Educação Infantil, 95\% no Ensino Fundamental e 47\% no Ensino Médio. Indagadas sobre realizar alguma atividade artística, $70 \%$ afirmaram que não realizam e os $30 \%$ das que responderam afirmativamente, indicaram as seguintes atividades mais citadas em ordem decrescente: dança, música, canto-coral, fotografia, pintura, artesanato, artesanato com Espuma Vinílica Acetinada (E.V. A), personalização de produtos para aniversário.

Questionadas sobre o que consideram que já sabem sobre arte, mencionaram artistas e técnicas/procedimentos artísticos. Dentre os 25 artistas mencionados pelas licenciandas, 20 são homens e cinco mulheres, sendo 13 artistas visuais, oito músicos e quatro do campo literário. Dentre os 13 artistas visuais -11 homens e duas mulheres- sete são de outras nacionalidades e seis brasileiros. Dentre os brasileiros, dois pertencem à região Nordeste. Dos oito músicos, todos são brasileiros, seis da região Nordeste e três são mulheres. Dos quatro artistas do campo literário, todos são homens da região Nordeste. Em relação aos saberes prévios que as licenciandas reconhecem e que fazem parte de seus repertórios, podemos afirmar que estes estão contaminados pela "narrativa do amo" (ORNER, 1999), a narrativa do homem branco, ocidental, que legitimou e naturalizou uma forma de pensar baseada nas oposições dualistas e excluiu aquelas faladas pelas mulheres brancas, não brancas e homens não brancos. Essa narrativa reforça a noção de artista que se autoproduz alheio a qualquer interesse e ou circunstância social.

Sobre suas expectativas para o percurso do componente curricular na Licenciatura, as mais mencionadas se relacionam com o ensino, como: "adquirir conhecimento sobre arte, para aplicá-lo em sala de aula", "aprender a utilizar as

SARDELICH, Maria Emilia. Encontros com a arte em autobiografias de licenciandas em pedagogia. .Revista da FUNDARTE, Montenegro, p.69-88, ano 19, oㅜ 39, julho/dezembro de 2019.

Disponível em: http://.seer.fundarte.rs.gov.br/index.php/RevistadaFundarte/index $>20$ de dezembro de 2019. 


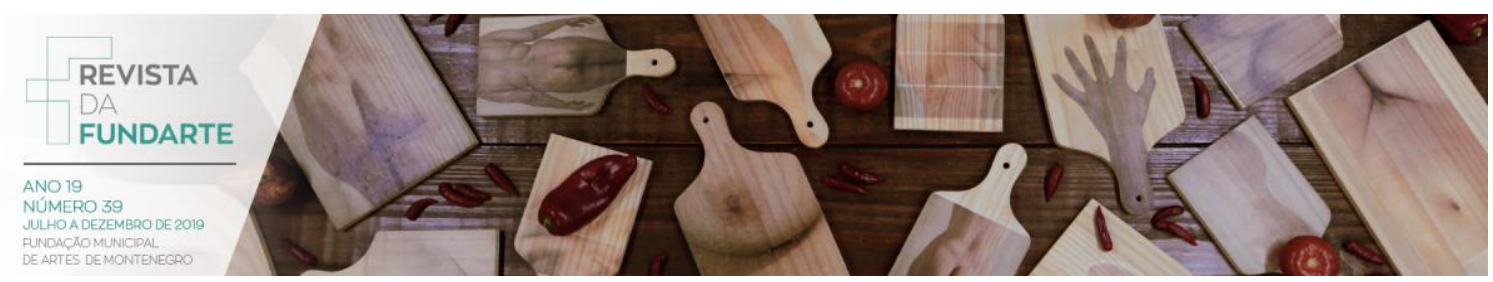

várias ferramentas artísticas para quando estiver lecionando", "aprender a desenvolver atividades para praticar com meus alunos", "saber usar as linguagens artísticas para melhor dinâmica da minha atuação como pedagoga", "utilizar a arte como meio de promover a aprendizagem", "usar o ensino de artes para contribuir na sala de aula", "ensinar arte e ludicidade", "aprender a ensinar artes, mesclando teoria e prática", "inserir a Arte como ferramenta facilitadora de aprendizagem", "aprender sobre arte e métodos para ensinar os alunos", "usar a arte de forma lúdica". Considerei que as expectativas das licenciandas em relação ao Ensino da Arte, se aproximavam de uma noção instrumental da "competência técnica" (VEIGA, 1999), da reprodução de conteúdos homogeneizados concebendo a atividade profissional, dirigida à aplicação de técnicas. Essas expectativas se confrontaram com o posicionamento docente de problematizar as implicações das escolhas didático-pedagógicas no ensino de arte para a relação entre pessoas e coletivos, como também valorizar a atividade docente como prática criativa e criadora.

\section{AS NARRATIVAS SOBRE ARTE}

Ainda no momento da avaliação diagnóstica, as licenciandas foram indagadas sobre o que pode ser aquilo que designamos arte. Para 96\% das licenciandas, a arte refere-se à expressão de sentimentos, emoções, explicando como "Tudo aquilo que possa representar ou expressar sentimentos", "Expressar seus sentimentos de forma que Ihe faça bem", "Algo criado pelo ser humano para expressar um sentimento", “Aquilo que expressa”, "A forma de expressão de uma pessoa ou mais”, "Arte pode ser tudo que toca a nossa sensibilidade de alguma forma", "A expressão diversa e significante de formas de viver", "Uma forma de expressar emoções através de habilidades", "Tudo que envolva criação, recriação e criatividade", "Para mim, a arte é a forma de se expressar de varias maneiras"; 2 \% indicaram algo que se relaciona com a cultura, como "Arte é tudo aquilo que envolve cultura" , "Algo que expressa a história e cultura da pessoa e de um povo", "Uma forma de leitura da realidade, representação da vida" e $2 \%$ indicaram uma concepção instrumental de arte como meio para aprender de forma prazerosa: "Uma forma prazerosa de aprender, de ensinar e de diagnosticar dificuldades facilidades e habilidades de cada

SARDELICH, Maria Emilia. Encontros com a arte em autobiografias de licenciandas em pedagogia. .Revista da FUNDARTE, Montenegro, p.69-88, ano 19, oㅜ 39, julho/dezembro de 2019.

Disponível em: http://.seer.fundarte.rs.gov.br/index.php/RevistadaFundarte/index $>20$ de dezembro de 2019. 


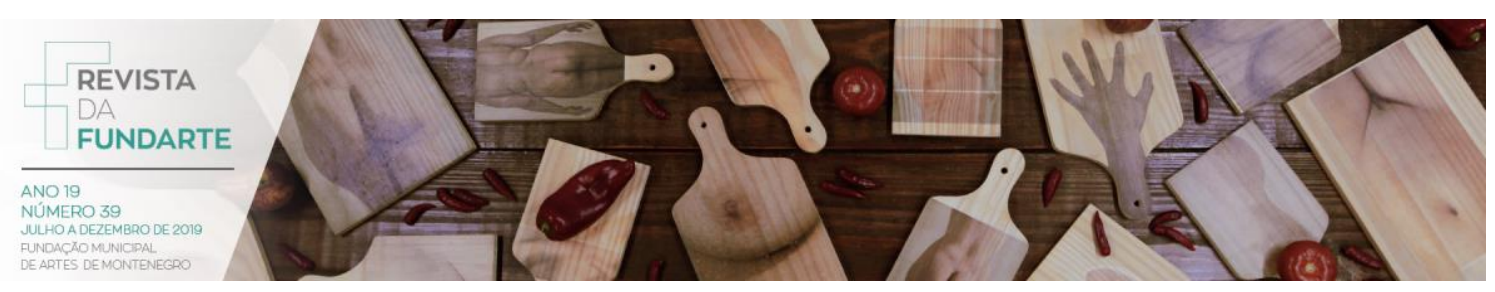

sujeito", "Um instrumento que o aluno pode identificar-se a si mesmo em aptidões ainda desconhecidas e como instrumento de socializar-se" "Tudo que é feito para aprender de modo lúdico".

A concepção de arte como expressão dos sentimentos já foi analisada por Penna; Alves (2001) e vigora a partir do Romantismo, movimento artístico de finais do século XVIII e início do século XIX, de grande impacto e aceitação em diferentes segmentos sociais. O Romantismo marca uma reação ao Classicismo e ao Neoclassicismo e seus ideais de razão, ordem, simetria e harmonia, em favor da emoção, imaginação e assimetria, valorizando a sensibilidade e o postulado de que antes de compreender é necessário sentir. Desse modo, o sentimento torna-se a mola propulsora da produção artística que resgata princípios de composição do barroco, devido ao dinamismo na composição diagonal, predomínio das formas curvas, sinuosas sem precisão de detalhes. Esse ideário manifesta-se naquelas correntes educacionais que propõem a livre-expressão, que defendem a pureza e inocência da criança. Também é responsável pela concepção de que a espontaneidade é a força motriz da criação genial. Nesse ideário exalta-se a genialidade do artista, que seria o verdadeiro tema da obra de arte, e sua produção imaginativa que sustenta as noções de expressão e comunicação da arte.

Constatado esse romântico modo de ver a arte que as licenciandas trazem ao chegar às aulas, provoquei para a produção da narrativa autobiográfica. No momento da proposição da atividade foi possível perceber certa resistência ao recurso da memória, com manifestações sobre as poucas lembranças do passado familiar e muito menos em relação à escola ou às "aulas de arte". Persisti no desafio de trabalhar com a memória, que se alimenta de vagas e flutuantes lembranças, que requer uma pausa, uma suspensão, uma vagarosa atenção de e para si ao cotidiano de ontem e de hoje, nesse hiperativo tempo do espaço de hipermobilidade, (SANTAELLA, 2013) em que vivemos. Com o auxílio de Nora (1993), busco esclarecer as estudantes de que a memória se enraíza no concreto, no gesto, na imagem, no objeto, que se alimenta de lembranças particulares ou simbólicas, sendo um fenômeno sempre atual, um elo vivido no eterno presente. Estimulei as licenciandas com as ideias de Bosi (2003), ao destacar que sempre estaremos

SARDELICH, Maria Emilia. Encontros com a arte em autobiografias de licenciandas em pedagogia. .Revista da FUNDARTE, Montenegro, p.69-88, ano 19, oㅜ 39, julho/dezembro de 2019.

Disponível em: http://.seer.fundarte.rs.gov.br/index.php/RevistadaFundarte/index $>20$ de dezembro de 2019. 


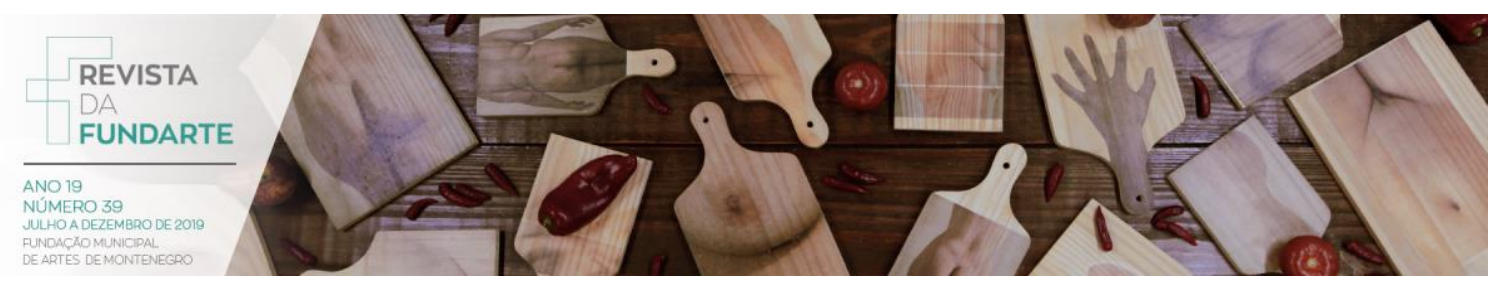

ausentes dos fatos narrados, que essa colheita de lembranças nos oferecerá a possibilidade de uma interpretação do que ainda podemos fazer.

Partindo desses pressupostos, a produção das narrativas se iniciou e foram sendo partilhadas coletivamente ao longo do semestre. O momento da comunicação oral do relato carrega a emoção da "presença que se pensa a si mesma, que se sabe presença, que intervém, que transforma, que fala do que faz, mas também do que sonha; que constata, que compara, avalia, valora, que decide, que rompe" (FREIRE, 2000, p. 112). Em geral, a contação das licenciandas se fez em ordem cronológica, referindo-se ao contexto familiar como um tempo anterior à escola e, em alguns relatos esses tempos se entrelaçam.

"Me aproximei da arte com o rádio a pilha, na casa dos meus pais/avós, numa casinha de sítio, na zona rural do cariri paraibano. Lembro bem do rádio e das músicas que gostava de ouvir. Em casa também tinha retratos na parede: meu avô e minha avó. Também tinham as fotografias em caixinhas, chamadas monóculos. Vez por outra, quando íamos a cidade, víamos televisão na casa de alguém, pois não havia energia elétrica na minha casa até meus 11 anos de idade, aproximadamente. Me vem à memória as lamparinas, feitas com lata e pavios de algodão e, com elas fazíamos sombras nas paredes usando as mãos. Esse foi o cenário onde eu cresci e esses foram os meus primeiros encontros com a arte".

"Minha família é de origem humilde, não possui muito acesso e recursos que Ihes permitissem proporcionar momentos de enriquecimento cultural. Desde que me entendo por gente meu maior contato com a arte, em meu contexto familiar, foi com a música. Minha avó materna era lavadeira de roupas, cresci escutando ela cantar boleros".

"Me lembro que meu primeiro contato com a arte foi desde muito cedo, pois escutava músicas na vitrola de minha vó. Desenhava nas paredes da minha casa. Assistia aos programas musicais no final da ditadura em 1985. Sempre tive esse leque de ofertas, até mesmo porque meus pais sempre estiveram nesse meio".

"Na minha família existem três tios e meu avô paterno que são repentistas. Meus parentes gostam bastante desse tipo de manifestação artística e foi assim que me aproximei da arte. Até hoje quando retorno para minha cidade no interior, meu avô

SARDELICH, Maria Emilia. Encontros com a arte em autobiografias de licenciandas em pedagogia. .Revista da FUNDARTE, Montenegro, p.69-88, ano 19, oㅜ 39, julho/dezembro de 2019.

Disponível em: http://.seer.fundarte.rs.gov.br/index.php/RevistadaFundarte/index $>20$ de dezembro de 2019. 


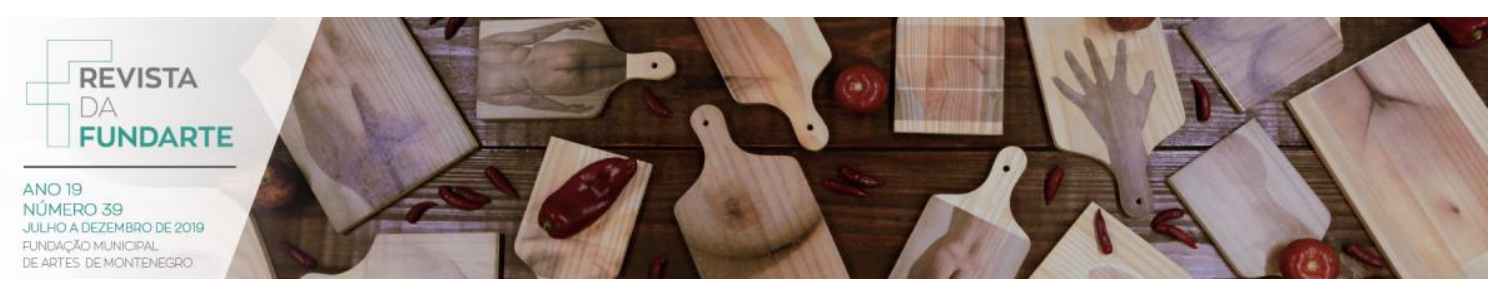

canta minha canção favorita que é de sua autoria e se intitula 'Lembrança de minha terra"'.

"Minha experiência com a arte começa na barriga de minha mãe - é o que todos dizem - escutando meu pai, músico, violonista, tocar e cantar. Através de meu pai conheci os mais diversos tipos de instrumentos e gêneros musicais".

"A minha vivência com a arte se deu mesmo antes da minha chegada à escola, 0 meu encontro com a música, uma das formas de arte. Foi quando criança ouvia já as melodias que os meus irmãos mais velhos gostavam de ouvir. Uma das músicas que me marcam até hoje é 'As quatro estações'. Essa música sempre estava associada à vinculação de uma programação que existia no horário da manhã, antecedendo minha ida para a escola. Ela, ainda hoje, me emociona".

"Em minha infância meu encontro com a arte primeiramente foi com a Música, já que meu pai era dono de uma churrascaria que nos finais de semana tinha música ao vivo. Era mais música MPB e forró raiz".

"Desde pequena as minhas referências em música tem sido as religiosas. Meus pais e meus avós, muito católicos, sempre as escutavam desde que eu era pequena, e assim fui aprendendo elas naturalmente. Minhas tias gostavam de forró, assim eu também fui aprendendo essas músicas".

"Os encontros que tive com a arte na caminhada da vida foram através de um familiar, pelo fato do mesmo participar de bandas musicais. Essa convivência me permitiu um repertório da música popular brasileira. As imagens fazem parte da minha vida, e o cinema sempre me atraiu".

"Arte na minha vida chegou pela música, que sempre esteve presente. Meus pais gostavam muito de música e ouvíamos diariamente. De sertanejo aos ritmos internacionais. Ainda hoje escuto essas músicas. Minha mãe sempre gostou de artesanato: bordar, pintar, costurar, fazer renda renascença”.

"Incialmente evidencio minha ligação com a música. Muito nova eu, minha irmã e prima criamos um grupo musical que consistia em ensaios e mini apresentações caseiras para nossa família. Nos divertíamos demais. A música foi presente no meio familiar, pois minha família possui afeição por música e ainda pequena ouvia discos

SARDELICH, Maria Emilia. Encontros com a arte em autobiografias de licenciandas em pedagogia. .Revista da FUNDARTE, Montenegro, p.69-88, ano 19, oㅜ 39, julho/dezembro de 2019.

Disponível em: http://.seer.fundarte.rs.gov.br/index.php/RevistadaFundarte/index $>20$ de dezembro de 2019. 


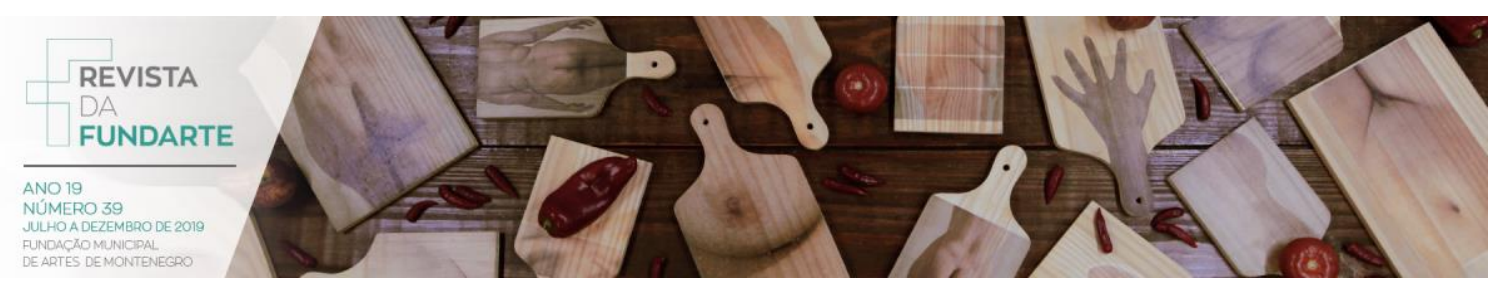

direcionados ao público infantil de várias cantoras gospel, pois nasci em um lar evangélico".

"Meu primeiro encontro com a arte foi através da música, pois desde pequena cantei nos corais da igreja que participo até hoje".

"Eu vim de uma família muito humilde, isso não significa que eles não compreendessem ou soubessem o que seria arte. Havia a música, e eu amava as obras musicais de Luiz Gonzaga, a maneira como ele falava do seu sertão nordestino".

"Meus primeiros encontros com a arte foram na infância, cresci em meio dos artesanatos de minha mãe e avós. Minha mãe fazia panelas de barro, flores de papel, costurava, fazia crochê e a renda filé, muito popular em minha cidade, pois as rendeiras ficam nas portas com seus 'teás' [teares] de madeira, bordando lindas peças. Meu avô tocava instrumento de percussão e esculpia em pedaços de madeira alguns instrumentos de sopro, tipo apitos com sons variados. Cresci ouvindo as bandas de música".

"Eu tinha um tio que era um exímio desenhista. Sua mão corria por entre o papel em branco, e de repente, os traços começavam a assumir formas e contornos que eram reconhecidos por nós. Em uma das casas que moramos, ele desenhou uma mulher na parede do quarto, que mesmo depois de várias mãos de cal, de tinta, o contorno dela poderia ser acompanhado pelo olhar atento de quem dormisse naquele quarto".

As autobiografias dessas licenciandas indicam vários aspectos a se considerar na formação docente. Destaco o aspecto do convívio familiar das estudantes com as manifestações artísticas. O caráter estético das relações humanas com os variados objetos do e no cotidiano emerge nas narrativas das licenciandas ao se referirem a esse tempo familiar. Para Canclini (1984) a relação estética com os objetos do e no cotidiano está condicionado pelo modo de produção e as classes sociais, pois a distinção da obra de arte dos demais objetos produzidos resulta "de convenções relativamente arbitrárias, cuja única 'legitimidade' é dada pelas necessidades do sistema de produção e pela reprodução das atitudes consagradas como estéticas pela educação" (CANCLINI, 1984, p.12). Os relatos das

SARDELICH, Maria Emilia. Encontros com a arte em autobiografias de licenciandas em pedagogia. .Revista da FUNDARTE, Montenegro, p.69-88, ano 19, oㅜ 39, julho/dezembro de 2019.

Disponível em: http://.seer.fundarte.rs.gov.br/index.php/RevistadaFundarte/index $>20$ de dezembro de 2019. 


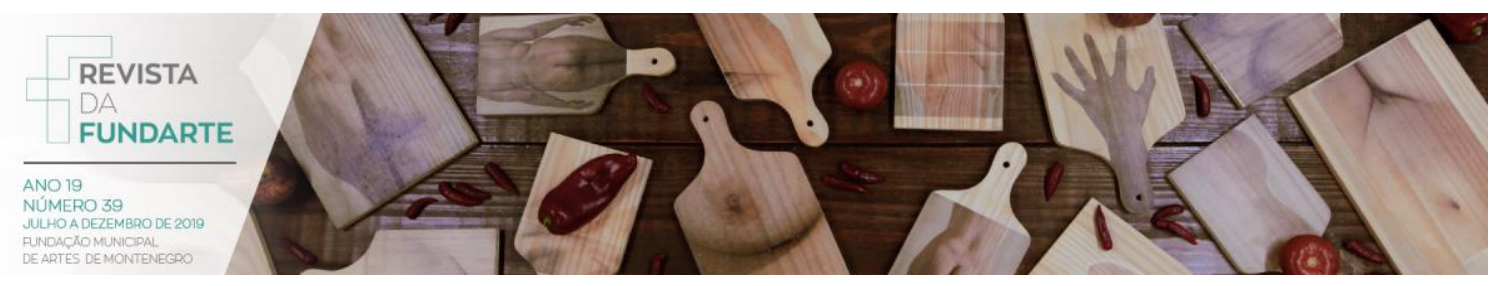

estudantes sinalizam como a família também designa os arbitrários culturais, apontando os objetos e fazeres merecedores de admiração e consumo que, nem sempre serão os mesmos selecionados pela instituição escolar. As licenciandas também destacam em seus contextos familiares os processos de produção artística, de recepção e como esses processos alteraram suas percepções de mundo. Assinalo que, em geral, ao se referirem a esse tempo de aproximação às manifestações artísticas no contexto familiar, a escrita das licenciandas é poética, emotiva e revela o investimento afetivo das narradoras.

Bosi (2003) observa que a fala emotiva e fragmentada das memorialistas traz consigo significações que nos aproximam da verdade, como também mostram a complexidade do real, as bordas que se tornam verdadeiras matrizes de projetos. Ao se referirem a esse tempo do contexto familiar aflora o lirismo da escrita, o que permite às licenciandas brincarem com a linguagem e as imagens da infância, afastando-se da escrita e fala acadêmica. Seus relatos abrem a porta para um delicado transver poético de seus contextos familiares, nos quais a arte fez acontecer algo em suas existências, Ihes afetando de algum modo e produzindo afetos, deixando efeitos e vestígios (LARROSA, 2011).

O investimento afetivo de uma escrita poética referente ao tempo familiar contrasta com a aridez expositiva do tempo escolar, e conecto este fato com constatação de Martins (2015). Para as licenciandas que participaram nessa contação autobiográfica, a música, em seus múltiplos usos e funções sociais (MAFFIOLETTI, 1993), de prazer estético, divertimento, reação física, integração social, validação de instituições, rituais e conformidade a normas sociais, é a manifestação artística que predomina em seus contextos familiares, contrapondo-se ao fato das artes visuais se destacarem nos currículos das Licenciaturas em Pedagogia, como apontado por Martins (2015) em pesquisa sobre ementas e bibliografias do componente curricular Ensino de Arte. Em geral, as artes visuais emergem no relato dessas licenciandas, quando estas se adentram no tempo escolar.

" $A$ respeito da minha experiência com a arte na escola, eu não recordo muitas coisas, mas havia muita escassez, no que se referia a conteúdo e aulas. Lembro-me

SARDELICH, Maria Emilia. Encontros com a arte em autobiografias de licenciandas em pedagogia. .Revista da FUNDARTE, Montenegro, p.69-88, ano 19, oㅜ 39, julho/dezembro de 2019.

Disponível em: http://.seer.fundarte.rs.gov.br/index.php/RevistadaFundarte/index $>20$ de dezembro de 2019. 


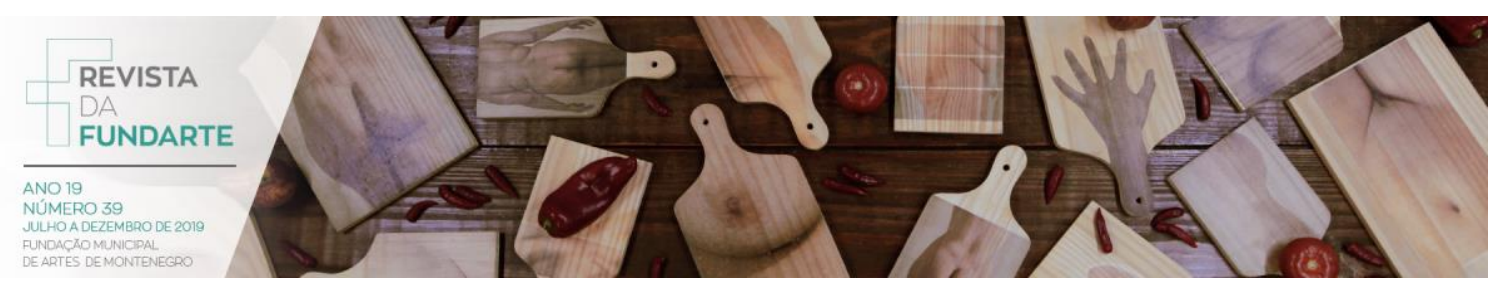

apenas do professor Valdir e de algo que ele propôs. Fizemos uma produção artística, que eu nunca esqueci. Ele nos pediu para comprarmos um vaso de barro e na sala de aula desenhamos nesse vaso o que queríamos e depois pintamos. Possuo esse vaso até hoje como recordação".

"As poucas recordações que tenho no ensino fundamental é a de uma professora que pedia para fazermos, às vezes, desenho livre, ou nos entregava a capa da prova para pintar de acordo com o tema da unidade. Por exemplo, o coelho da Páscoa, o casal matuto com a fogueira de São João, deixando uma capa já pintada como modelo no quadro e nós reproduzíamos com as mesmas cores. Não podíamos usar a nossa criatividade, pois isso significava fazer uma pintura diferente e feia. Também participei de aulas de bordado e confeitaria. Era o momento que apenas nós, meninas, saíamos da sala de aula e íamos para o pátio da escola aprender a bordar e confeitar. Não sabíamos os objetivos daquelas aulas, mas para quem estava acostumada a só colorir o papel, isso foi um diferencial'.

"Não me lembro da disciplina de artes, mas nas festas juninas o colégio se preparava para as festas tradicionais de São João, e os alunos se caracterizavam com roupas coloridas, chapéu de palha, e se formava o casamento dos matutos. Se colocava uma música no ritmo junino e a dança começava. Todos os convidados se maravilhavam em ver seus filhos dançando. Outro momento de datas comemorativas, por exemplo, era o dia das mães, sempre havia homenagem para elas. Nessa festa havia música, declamação de poemas, rosas jogadas para as mães".

"Durante minha vida escolar, poucas foram às experiências que tive com o mundo da arte. Lembro que na alfabetização as professoras pintavam nossos rostos de acordo com as datas comemorativas: dia do índio, Páscoa, dia da árvore".

"Na vida escolar a arte sempre foi aquela última aula da sexta-feira, quando nós já estávamos cansados e as professoras não estimulavam, só queriam que, como de costume, fizéssemos o desenho de nossa preferência. O meu desenho preferido era a minha casa na zona rural'.

"Na escola, a arte era vista como uma matéria que cuidava das comemorações das datas nacionais, momentos em que a professora utilizava para aquietar a turma

SARDELICH, Maria Emilia. Encontros com a arte em autobiografias de licenciandas em pedagogia. .Revista da FUNDARTE, Montenegro, p.69-88, ano 19, oㅜ 39, julho/dezembro de 2019.

Disponível em: http://.seer.fundarte.rs.gov.br/index.php/RevistadaFundarte/index $>20$ de dezembro de 2019. 


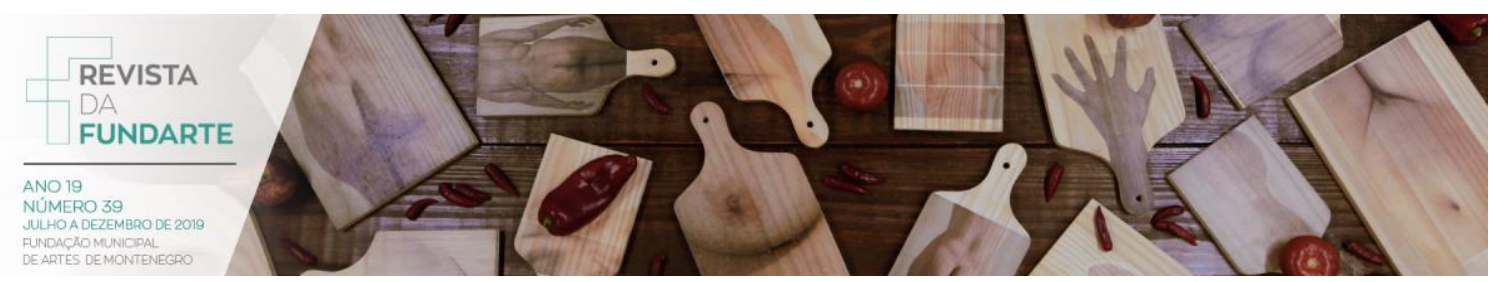

pesquisando sobre a data comemorativa. No ensino fundamental II tive a experiência com uma professora que em todas as aulas apresentava os grandes pintores e fazia prova com perguntas sobre a vida do artista".

"Na minha formação escolar não tive momentos marcantes. A partir do fundamental Il meu contato com a arte na escola era apenas teórico, de modo que eram escritos textos no quadro e copiar".

"Na escola, as atividades eram basicamente pintar, colar, desenhar, modelar com massinhas e fazer misturas com tintas. Fora da escola tive muito contatos com a arte".

"Nas aulas de educação artística era mais para pintar com tinta a guache, algum desenho, e brincar com massinha. Era mais atividades para passar o tempo. Depois de adolescente, também não me lembro de na escola em que frequentava ter aulas de arte".

"Vivências com arte na escola, lembro-me que nos primeiros anos as professoras nos mandavam desenhar. Na quinta e sexta séries lembro-me das aulas de arte que consistiam em conhecer a vida de artistas da pintura. Não tenho memória de nenhuma atividade prática, só das aulas teóricas".

"Na escola guardei algumas atividades feitas por mim no componente curricular arte, colagem com papel emborrachado e mosaico, no terceiro ano do ensino fundamental. Todas as datas comemorativas eram lembradas e trabalhadas na capa das provas".

"Artes foi uma disciplina da qual sempre gostei muito. Nessa época éramos os responsáveis pelas capas que compunham nossas atividades bimestrais, geralmente, a professora levava um modelo com as cores desejadas e tínhamos que fazer exatamente igual, normalmente essas capas vinham com datas comemorativas: Dia do Índio, Páscoa, Dia das Mães, São João, Natal. Outra lembrança forte é em relação às festas juninas e sempre tínhamos pausa nas aulas para ensaiar".

"Na escola, nos primeiros anos, a pintura de desenhos se faz presente, assim como o trabalho com massinhas modelando objetos de forma prazerosa. No Ensino

SARDELICH, Maria Emilia. Encontros com a arte em autobiografias de licenciandas em pedagogia. .Revista da FUNDARTE, Montenegro, p.69-88, ano 19, oㅜ 39, julho/dezembro de 2019.

Disponível em: http://.seer.fundarte.rs.gov.br/index.php/RevistadaFundarte/index $>20$ de dezembro de 2019. 


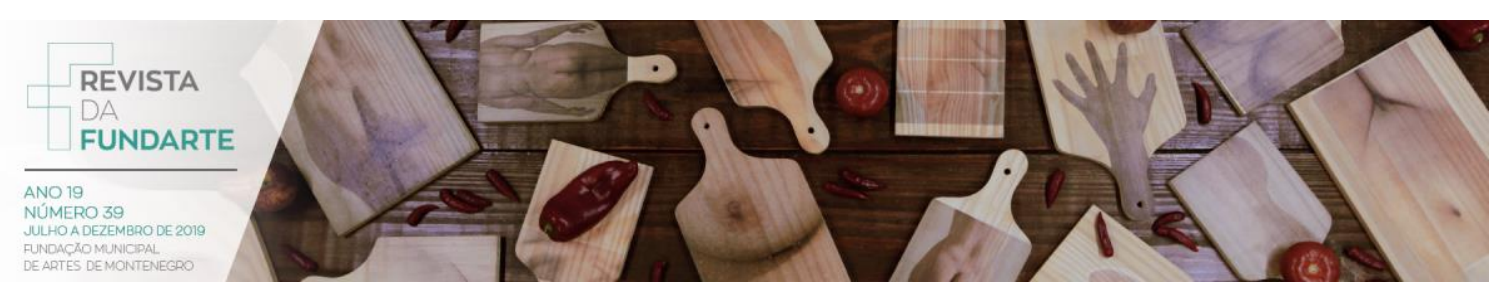

Fundamental, lembro que minhas professoras trabalhavam as datas comemorativas, nas capas de provas, sempre pintava desenhos referentes à alusão da data".

"Quando penso no ensino básico, não me vem nada grandioso, nem nada com detalhes. Arte no Ensino Fundamental I se resumiu a colorir desenhos prontos. Quando saí do Fundamental I, passei a ter professores específicos que priorizavam a reescrita, retirar do quadro e copiar o conteúdo no caderno de modo exaustivo. No Ensino Médio, no primeiro ano, não foi diferente".

"Na escola que estudei, a Educação Infantil era muito tradicional, e tínhamos poucos materiais relacionados à arte. No Ensino Fundamental não mudou muito. Lembro que após as férias, as professoras pediam pra desenhar o que fizemos nas férias. Eram tantas coisas que eu sempre ficava em dúvida sobre o que deveria desenhar. $\mathrm{Na}$ antiga quarta série eu mudei de escola, fui estudar em uma escola pública e lá não tive boas experiências com os professores de arte. A maioria queria nos ensinar conteúdos muito teóricos, que envolviam artistas famosos como: Salvador Dali, Picasso, Da Vinci, Monet, Van Gogh, Portinari. Não desmerecendo a importância desses artistas, mas para aquela idade na época não era um conteúdo interessante e motivador".

As narrativas das licenciandas indicam que estas reconhecem a formação em arte durante a Educação Básica, predominantemente, no Ensino Fundamental, com destaque para as artes visuais, porém não identificam que essa formação tenha colaborado para o desenvolvimento de suas habilidades de desenhar, pintar, modelar. A aridez de suas memórias escolares indica atividades pouco significativas, como reprodução de desenhos estereotipados, relacionados a datas comemorativas, em capas de provas. Salientam produção de desenho e outros procedimentos artísticos, como pintura, colagem, modelagem com massinha, sempre como escolhas de docentes para discentes, sem preocupação de indicar porque, nem onde ou como se pretendia chegar a algum lugar. Essas narrativas, mesmo que de estudantes de diferentes idades e municípios, referem-se a uma comum, triste e anacrônica prática escolar que privilegia a mera informação sobre a criação, de um simples fazer passar o tempo, passar o dia, a semana, o bimestre, o ano, entre informações sobre artistas e obras muito alheias às suas produções escolares.

SARDELICH, Maria Emilia. Encontros com a arte em autobiografias de licenciandas em pedagogia. .Revista da FUNDARTE, Montenegro, p.69-88, ano 19, oㅜ 39, julho/dezembro de 2019.

Disponível em: http://.seer.fundarte.rs.gov.br/index.php/RevistadaFundarte/index $>20$ de dezembro de 2019. 


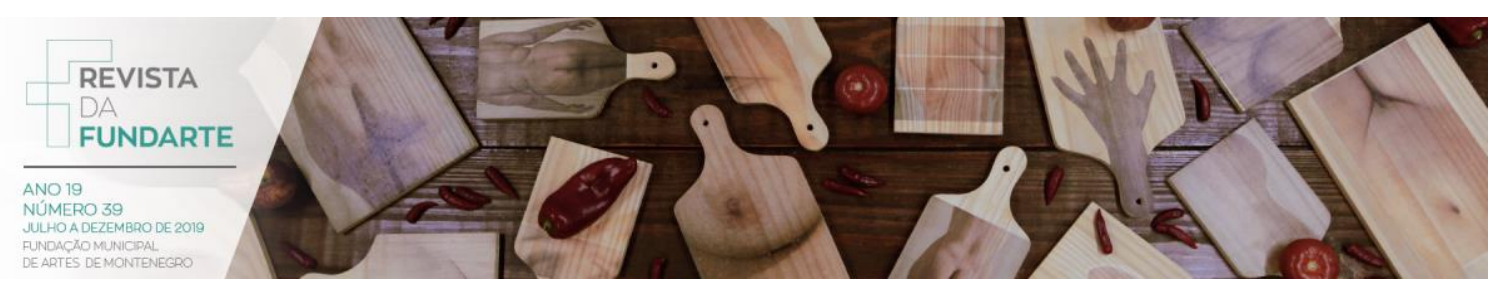

Essas narrativas me levam a questionar o sentido desse trabalho no contexto escolar e as dificuldades institucionais de ver o processo artístico como prática de investigação, seja da forma, do conteúdo, da materialidade e do processo de criação, como reinvenção do mundo; de desafiar a capacidade criadora e a curiosidade, "que nos caracterizam como seres humanos e não deixá-las entregues ou quase entregues a si mesmas. Pior ainda: dificultar o seu exercício ou atrofiá-las com uma prática educativa que as inibe" (FREIRE, 2000, p. 57).

\section{AS PALAVRAS DESACOSTUMADAS}

Como docente/investigadora, busquei compreender os modos de ver a arte que as licenciandas traziam em suas bagagens. Essas constatações fazem parte de um percurso, uma parada necessária para um pensar que não pretende se adaptar, nem se converter, aos modos de ver das licenciandas, nem tampouco impor-lhes arrogantemente um outro como verdadeiro, mas são necessárias para as escolhas e decisões docentes, como "tempo de possibilidade" (FREIRE, 2000, p. 28). Assim, com o mesmo cuidado que solicitei às licenciandas olharem para a própria formação, a fim de perceberem como esta aconteceu na Educação Básica, iniciamos uma delicada indagação sobre a permanência desses modelos hoje. Se essa formação não produziu satisfação, posto que não se sentem capazes de trabalhar com as manifestações artísticas, o que justificaria a reprodução de tais modelos? A quem beneficia a manutenção desses anacrônicos e imobilizadores modelos?

A partir dessas indagações, iniciamos um processo de desaprendizagem (JOSSO, 2012) das experiências escolares com a arte. Esse processo requer desacostumar palavras e fazeres anacrônicos que atrofiam a curiosidade e a capacidade criadora. Juntas buscamos construir um outro modo de olhar para a arte, como possibilidade de crescermos no exercício de pensar, de indagar e indagar-se, "de programar e de não apenas seguir os programas a elas, mais do que propostos, impostos" (FREIRE, 2000, p. 28).

Nesse processo de desaprendizagem buscamos construir um modo de ver descontar a narrativa do amo e da autoexpressão individual, para contar a da arte 


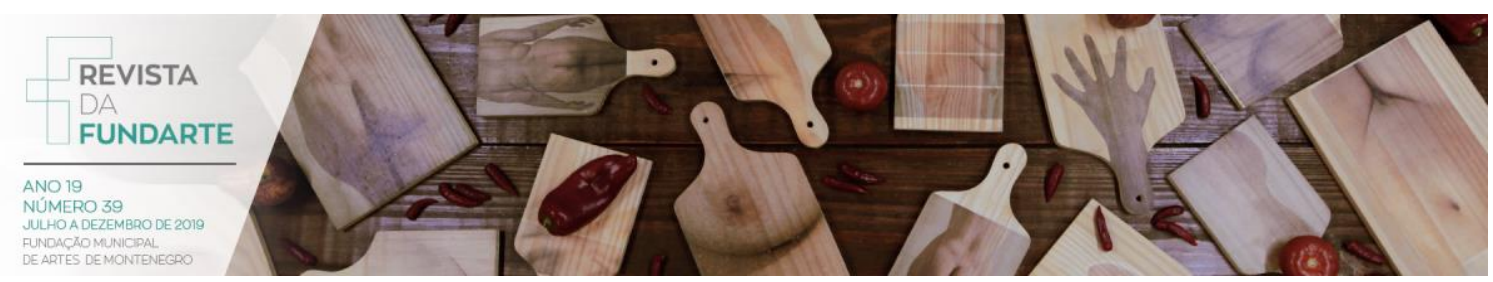

relacional, como um conjunto de práticas artísticas que visam em seus meios e finalidades as relações sociais, a dimensão a(r)tivista de forma comunitária, desmanchando fronteiras entre projetos sociais e artísticos, investigando as possíveis relações entre uma comunidade e um projeto artístico individual ou coletivo. Um modo de ver que decolonize os cúmplices conceitos de arte e estética para desobrigar a subjetividade. No entendimento eurocêntrico de arte, uma de suas funções é influenciar e afetar os sentidos, as emoções e a inteligência, e a função da filosofia estética entender o sentido da arte. Para as "estéticas decoloniais" (MORENO; MIGNOLO, 2012), tanto os processos do fazer, quanto seus produtos e entendimentos começam por aquilo que a arte e estética eurocêntricas ocultam, que é a ferida colonial.

Moreno; Mignolo (2012) afirmam que a ferida colonial influencia os sentidos, as emoções e a inteligência. No caso da arte e da estética, a ferida colonial é sentida nas emoções e na inteligência, por aquelas pessoas que operam com elementos simbólicos que afetam os sentidos, as emoções e o intelecto, mas não são considerados artísticos e isso se legitima no discurso filosófico que define a estética como a disciplina que investiga o sentido da arte. Desse modo, as estéticas decoloniais operam com elementos simbólicos que buscam desmontar o mito ocidental da arte e da estética para decolonizá-las, desobrigando a subjetividade que, para inserir-se no sistema da arte orienta seus fazeres para satisfazer os critérios desse sistema colonialista.

O processo de desaprendizagem subverte os papéis e atribuições de legitimação da produção artística reconhecendo essa função a pessoas que habitualmente não as exercem, como as licenciandas que consomem compulsivamente música, ilustrações, séries, filmes, histórias em quadrinhos, entre muitos outros artefatos culturais nos espaços de hipermobilidade em que habitam, mas não se autorizam a emitir um juízo sobre essa produção. Também busca evidenciar a produção artística de mulheres no âmbito local, nacional e internacional, incluindo objetos, agentes e instituições ausentes da perspectiva tradicional da História da Arte, na perspectiva de alargar a abrangência desse relato e construir uma narrativa plural, em processo, menos individualista, menos etnocêntrica, menos 


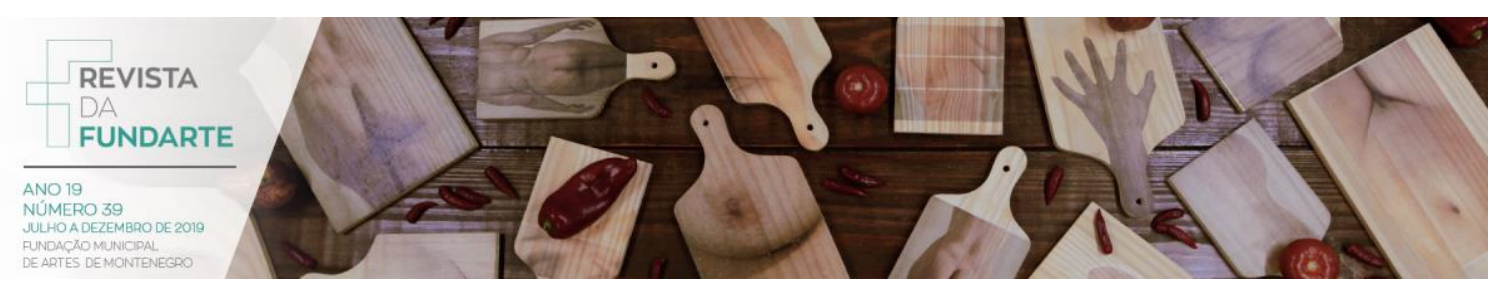

androcêntrica. Desse modo, as licenciandas se aproximam de produtoras que trabalham "narrativas enviesadas" (CANTON, 2009), que questionam a memória em um tempo turbilhonado, o corpo e padrões estéticos, o erotismo e a micropolítica das questões cotidianas como a ecologia, a violência doméstica, a educação, as políticas de gênero, dentre outros temas.

\section{CONSIDERAÇÕES ALCANÇADAS}

Considero que realizar este trabalho de investigação sobre a formação em arte a partir das autobiografias como fonte e percurso de pesquisa, para produzir conhecimento sobre essa formação e o seu sentido para as licenciandas, contribui para uma história do Ensino de Arte no Brasil mais plural, que não recorra somente às fontes secundárias, reinterpretando determinadas leituras já estabelecidas. Foi possível constatar que as licenciandas trazem em suas bagagens um modo de ver a arte como produto, a partir de um olhar romântico, voltado para a produção de um objeto belo que expressaria os sentimentos dos produtores.

As autobiografias privilegiaram a contação da vida em uma ordem cronológica, referindo-se ao contexto familiar como um tempo anterior à escola. Ao se referirem às práticas artísticas do contexto familiar, as narrativas são poéticas, emotivas, indicam que seus encontros com a arte lhes afetaram, produzindo efeitos e vestígios, contrastando com uma árida exposição referente ao tempo escolar. Seus relatos indicam aspectos importantes para refletirmos sobre a formação em arte e revisarmos ementas e programas. Destaco a significativa influência dos processos de produção artística, de recepção e como esses processos se inserem e alteram suas percepções no contexto familiar. Eles indicam o caráter estético das relações humanas com os variados objetos do e no cotidiano, bem como os arbitrários culturais que indicaram objetos e fazeres merecedores de admiração e consumo em suas vidas que, em geral, não coincidiram com os selecionados pela instituição escolar.

Os vestígios desses encontros com a arte no contexto familiar são musicais, dando a ver o prazer estético, o divertimento, a integração social, bem como os rituais sociais. Por outro lado, esse prazer estético com a manifestação musical 


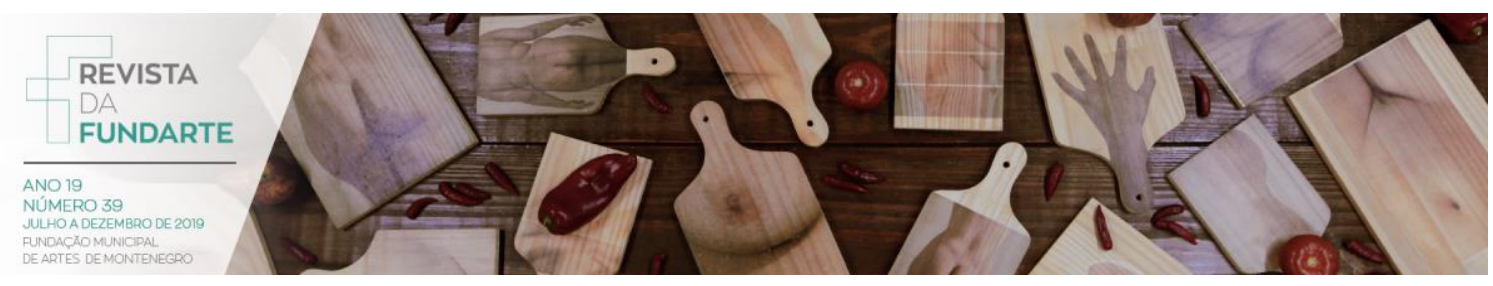

quase desaparece na instituição escolar, permanecendo na comemoração de festas juninas, dando passagem às artes visuais que pouco exploraram a capacidade criadora dessas licenciandas.

As narrativas dessas licenciandas continuam me questionando sobre os obstáculos epistemológicos para revisarmos ementas e programas, que nos impedem de criar e trabalhar de outra forma que não a da arte como produto, e intensificar processos relacionais, abertos à presença de muitas vozes e modos de existência. Elas também sinalizam a urgência da desaprendizagem das práticas artísticas escolares anacrônicas, para estabelecermos uma relação de autoconfiança com nossa produção pessoal e coletiva, para descontar a narrativa do amo, para decolonizar os cúmplices conceitos de arte e estética, para desobrigar a subjetividade autoexpressiva e expor nossas feridas coloniais, para subverter os papéis e atribuições de legitimação da produção artística que afirme o diálogo com as nossas memórias e lembrar-nos de que nossas vidas importam.

\section{Referências:}

BOSI, Eclea. O tempo vivo da memória: ensaios de Psicologia Social. São Paulo: Ateliê Editorial, 2003.

CANCLINI, Néstor Garcia. A socialização da arte: teoria e prática na América Latina. São Paulo: Editora Cultrix Ltda, 1984.

CANTON, Katia. Temas da Arte Contemporânea. São Paulo: WMF Martins Fontes, 2009.

CLANDININ, D. Jean; CONNELLY, F. Michael. Pesquisa narrativa: experiência e história em pesquisa qualitativa. 2 ed. Uberlândia, MG: EDUFU, 2015.

CUNHA, Susana Rangel Vieira. Uma arte do nosso tempo para as crianças de hoje. In: CUNHA, Susana Rangel Vieira; CARVALHO, Rodrigo Saballa de (orgs.). Arte Contemporânea E Educação Infantil. Porto Alegre: Editora Mediação, 2017. p. 9-26.

. Cenários da Educação Infantil. Educação \&Realidade, n. 30, v. 2, p. 165 185, jul./dez. 2005.

FREIRE, Paulo. Pedagogia da indignação: carta pedagógica e outros escritos. São Paulo: UNESP, 2000. 


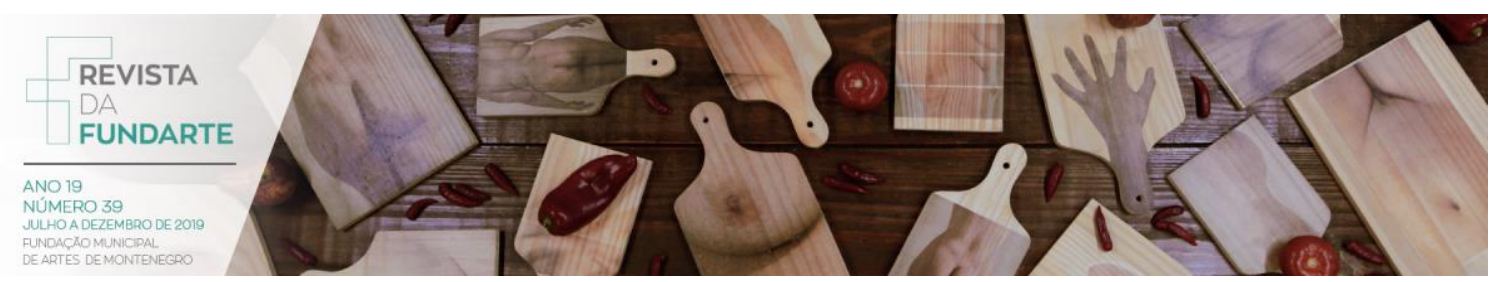

GUATTARI, Felix. As três ecologias. Campinas: Papirus,1990.

JOSSO, Marie-Christine. O corpo biográfico: corpo falado e corpo que fala. Educação \& Realidade, Porto Alegre, v. 37, n. 1, p. 19-31, jan./abr. 2012.

. Experiências de vida e formação. São Paulo: Cortez, 2004.

LARROSA, Jorge. Experiência e alteridade em educação. Revista Reflexão e Ação, Santa Cruz do Sul, v.19, n2, p.04-27, jul./dez. 2011.

MAFFIOLETTI, Leda de Albuquerque. As funções sociais da Música no contexto escolar. Cadernos de Formação - Educação Musical. Porto Alegre: Secretaria Municipal de Educação, 1993.

MARCELO, C. A identidade docente: constantes e desafios. Revista Formação Docente, v. 1, n. 1, ago.- dez. 2009.

MARTINS, Mirian Celeste. Artes visuais: 'a rainha' das linguagens artísticas nos cursos de pedagogia? Trama Interdisciplinar, São Paulo, v. 6, n. 2, p. 75-92, maio/ago. 2015

MIZUKAMI, Maria das Graças Nicoletti. Escola e aprendizagem da docência: processos de investigação e formação. São Carlos, SP: EdUFSCAR/INEP, 2002.

MORENO, Pedro Pablo Gomez; MIGNOLO, Walter. Estéticas decoloniales. Bogotá: Universidad Distrital Francisco José de Caldas, 2012.

NORA, Pierre. Entre memória e história: a problemática dos lugares. Projeto História, São Paulo, v. 10, p. 7-28, dez. 1993.

ORNER, Mimi. Interrumpiendo los llamados para una voz de el y la estudiante en la educación "liberadora". In: BELAUSTEGUIGOITIA, Marisa. Géneros profíguos. Barcelona: Paidós, 1999. p. 117-133.

PASSEGGI, Maria da Conceição; SOUZA, Elizeu Clementino de. O movimento (auto)biográfico no Brasil: esboço de suas configurações no campo educacional. Revista Investigación Cualitativa, v. 2, n. 1, p. 6-26, 2017.

PENNA, Maura; ALVES, Erinaldo. Marcas do romantismo: os impasses da fundamentação dos PCN Arte. In: PENNA, Maura (coord.) É este o ensino de arte que queremos? Uma análise das propostas dos Parâmetros Curriculares Nacionais. João Pessoa: Editora Universitária, 2001. P. 57-80.

SANTAELLA, Lucia. Desafios da ubiquidade para a educação. Revista Ensino Superior, Unicamp, 04/04/2013.

SARDELICH, Maria Emilia. Encontros com a arte em autobiografias de licenciandas em pedagogia. .Revista da FUNDARTE, Montenegro, p.69-88, ano 19, oㅜ 39, julho/dezembro de 2019.

Disponível em: http://.seer.fundarte.rs.gov.br/index.php/RevistadaFundarte/index $>20$ de dezembro de 2019. 


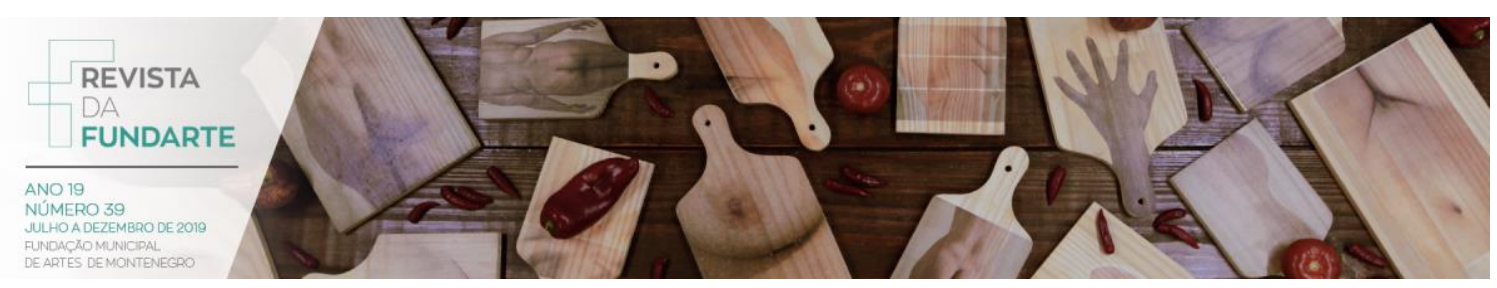

VEIGA, IIma Passos Alencastro. A Prática Pedagógica do Professor de Didática. 3 ed. Campinas: Papirus, 1996.

SARDELICH, Maria Emilia. Encontros com a arte em autobiografias de licenciandas em pedagogia. .Revista da FUNDARTE, Montenegro, p.69-88, ano 19, n 39, julho/dezembro de 2019.

Disponível em: http://.seer.fundarte.rs.gov.br/index.php/RevistadaFundarte/index $>20$ de dezembro de 2019. 